\title{
Triggering the development of electric mobility: a review of public policies
}

\author{
Fabien Leurent • Elisabeth Windisch
}

Received: 22 October 2010 / Accepted: 7 November 2011 /Published online: 24 November 2011

(C) The Author(s) 2011. This article is published with open access at SpringerLink.com

\begin{abstract}
Context The fundamental challenge of a massive deployment of electric mobility is the reduction of transportation's impact on climate. Hereby derived challenges specifically concern: (a) the organization of mobility together with the uptake of recharge infrastructure, (b) the interaction of the electric mobility system with the electricity net, hereby considering the energy storage function of batteries, (c) the technological progress and the industrial production of vehicles and various components. Overall, these stakes involve the community more than the individual vehicle user.

Objective This paper analyses public policies and projects in favour of electric mobility based on private or shared vehicle usage. An international review of national policies and regional projects is given. The conditions for availability and attractiveness of an electric mobility system to potential users are discussed, notably so with respect to the deployment of the recharging infrastructure and its adequacy to existing land-use patterns.

Conclusion Current policy approaches supporting the uptake of electric mobility are promising. For the time being, however, the complexity of the electromobility system impedes a valid conclusion on the effectiveness of measures put in place. Besides public policy intervention mainly also economic, technical and industrial factors will define the success of e-mobility. Upcoming years will allow first ex-post policy analyses.
\end{abstract}

\section{F. Leurent $\cdot$ E. Windisch $(\bowtie)$}

Université Paris-Est, Laboratory City Mobility Transport (LVMT),

6 et 8, avenue Blaise Pascal, Cité Descartes Champs-sur-Marne,

F-77455 Marne-la-Vallée Cedex 2, France

e-mail: elisabeth.windisch@enpc.fr

F. Leurent

e-mail: fabien.leurent@enpc.fr
Keywords Electric mobility · public policy · sustainable transport · challenges in mobility · international policy review $\cdot$ stimulation of electric mobility

\section{Introduction}

\subsection{Background}

The rise of the automobile began at the end of the 19th century with electrically powered vehicles, but the internal combustion engine became dominant from 1910 onwards, because of the advantages in size and range offered by liquid fuels. Car travel developed hugely over the 20th century as a result of technical progress and falling costs for infrastructure (routes, roads, equipment), vehicles (performance and reliability, comfort and ergonomics), systems (signage, traffic management) and services (fuelling, maintenance, insurance, rental and taxis). In the developed world, automobile infrastructures became widespread and the private car became the dominant method of individual transportation, enabling people to access a wide variety of activities both local and remote.

However, the car also generates problems: accidents, noise, air pollution and greenhouse gas emissions, consumption of increasingly rare and expensive fossil fuels. The last three forms of impact have become very significant issues of sustainable development: since they are associated with the internal combustion engine, one major way of reducing them is to use electrically powered engines.

Electric mobility has a low carbon footprint (provided that the electricity is not generated from fossil fuels), and can employ renewable energy. It has less local impact on noise levels and air quality. It entices green driving habits and quieter traffic conditions. However, it requires a battery, which is expensive and has limited range (in terms of journey distance). 


\subsection{Motivations for public action}

In short, replacing internal combustion vehicles with electric vehicles is advantageous to the community but more costly for the user. In order to achieve the community benefits, electric mobility needs to be made attractive to users, not just by developing its availability in terms of vehicles and charging infrastructure, but also by ensuring its long-term affordability over the lifespan of the vehicle, or rather throughout the period of vehicle ownership.

Availability All the components entailed in a car-based mobility system, as described in paragraph 1.1, are supplied by a number of players involved in a longterm complementary relationship. The shift to electric mobility primarily concerns the supply of energy and its local distribution to users, with a dense network of charging terminals. The authorities are in a strong position to encourage coordination and cooperation between the different suppliers.

Affordability To absorb the additional acquisition costs through energy savings, the essential condition is that the vehicle should be used to travel significant distances, typically more than $20,000 \mathrm{~km}$ a year, with strict constraints in terms of range. This condition can be met by intensive individual use, or by the vehicle being shared between different users for variable rental durations (from very short to long). An additional solution would be to cut acquisition costs by reducing the cost and improving the performance of batteries.

In the long term, therefore, the community can promote the development of electric mobility by ensuring availability and stimulating technical progress. It can also act in the short term, through various provisions to encourage electric vehicle ownership and use: tax incentives for purchase and ownership, lower prices for usage or parking, advantageous parking provisions, etc. This kind of provision would apply during a transitional phase, until the spread of electric vehicles reached the critical mass required to generate economies of scale in the production of vehicles and components.

Related issues Finally, the development of electric mobility is closely tied up with energy generation and industrial production, both of which are strategic issues for the community. The presence of large numbers of electric vehicles on the roads would require significant increases in electricity production, using green sources to ensure a positive impact on the environment. At the same time, the batteries would effectively become small reservoirs that could smooth out electricity production over time, with potential economic gains for the battery holder. As regards the industrial production of electric vehicles, in many industrialised countries the car industry plays a significant role in creating both jobs and value.

\subsection{Objective and scope of the paper}

We have defined the stakes of public policy to promote electric mobility. The main purpose of the article is to identify the targets and instruments of such a policy, through an international review of policy briefs, implementation plans and practical experiences. The specific object of electric mobility considered in this paper is the electric plug-in car (both, the plug-in hybrid electric car (PHEV) and the battery electric car (BEV) that in the following will be collectively abbreviated as EV - electric vehicle if not stated differently). So far the automobile has remained the main transport mode with regard to distances travelled in the Western World and constitutes therefore the main contributor to local and $\mathrm{CO} 2$ emissions.

In looking at public policy, we identified three distinct sectors: Industry, Energy, Mobility and related infrastructure. Each sector is associated with a specific spatial scale, primarily national for industrial and energy policy, primarily regional for mobility and the related infrastructure, but sometimes also for energy.

Two forms of transportation are concerned: the user-owned private car and the shared car owned by a rental company.

\subsection{Structure of the paper}

The remainder of this paper is structured into four sections. Section 2 provides a typology of political instruments in terms of policy targets. Section 3 looks at the following examples of national policy: Germany, United Kingdom, Spain, Denmark, France, Norway, USA, Japan, China and India. Also the European Union as a whole is regarded.

Section 4 examines three regional projects and policies: London's EV delivery plan, Germany's model regions with the example of North Rhine-Westphalia and the VLOTTE project in Vorarlberg, Austria. Finally, section 5 discusses the policies from a sustainable development perspective.

\section{Typology of policy instruments}

The introduction of a new mobility product, such as the electric vehicle, faces a variety of obstacles. Governments playing a key role for the development of an electromobility system can actively influence the whole market on its demand and supply sides. The gist of an International Energy Agency report on deployment strategies for new technology vehicles [1] is, however, that the scope of 
policy instruments influencing market development should go far beyond the traditional direct State regulations and financial incentives. Priority should be given to network management, where the State acts as facilitator. Platforms that include all actors of the mobility system should be established to develop a joint, economically viable strategy for an EV deployment. Such an approach is likely to be more time consuming but also more successful than massive programs aimed at selected, stand-alone targets. Of course a network management approach requires the setting of legislative regulations. Financial incentives can play an important, but only complementary role.

In the following a typology of possible governmental measures supporting the introduction of EVs is given. The categorization is in line with [1] and [2]; it also includes measures found in current policy intervention programs (see [3] and section 3).

Command and control instruments Are usually in the hands of public authorities and applied at a country wide level. Traditionally, they represent the core of a government's strategy that is then complemented by other types of instruments. Command and control instruments are neither costly for the public budget nor very time consuming for the government. Their effectiveness stems from their legally binding character that mainly obliges EV-system supplying stakeholders to provide products that conform to quality or safety standards. Also emission regulations or licensing procedures including environmental criteria can force developers and manufacturers to adopt cleaner technologies and create a trend towards EVs. The consumer side can be encouraged by including environmental criteria on issuing contracts for the purchase of public service vehicles; by mandates that enforce the inclusion of EVs into public sector fleets (or enforce vehicle retailers to sell a fixed percentage of EVs per year); by exempting EV users from restrictive regulations (as e.g. parking and driving restrictions). Command and control instruments are usually adapted to market and technological developments throughout time.

Economic instruments Are purported to overcome the cost barrier to EV development. These instruments support the development of EV technology or give financial incentives to potential buyers. Instances include direct investments in R\&D or infrastructure, preferential pricing policies (e.g. road pricing based on emissions, preferential parking fees), subsidies for EV purchase or EV infrastructure construction and tax incentives for EVs (e.g. concerning fuel taxes, circulation taxes/motor taxes, registration/purchase taxes). Also, special financing schemes that help overcome the barrier of high investment costs can be offered. Economic instruments should not be implemented as stand-alone measures, since the diffusion of an innovative technology requires behavioural changes that involve a set of conditions broader than financial incentives.

Procurement instruments Are aimed to push the demand for clean vehicles, hence to increase the number of them and enable for scale economies in their production. A government or a consortium of stakeholders decides to purchase a set of clean vehicles, of which the number enables them to benefit from reduced prices. Also, initiators of an EV program can decide to use EVs and take leadership by example by spreading information about their experiences. 'Green' procurement for public and industrial fleets can be introduced on a voluntary or mandatory basis.

Collaborative instruments Pertain to the network management approach by a government, based on the principle that the State should exert a collaborative and managing role in the society and the markets. The government takes a coordinating role between manufacturers, researchers, authorities and customers. Certifications and labels can be introduced for improving transparency and diffusion of information on the market; voluntary agreements between manufacturers and public authorities are decided; public-private partnerships favouring new mobility practices are established.

Communication and diffusion instruments Consist in informing and educating the public in order to develop their interest for and acceptance of EVs. Simultaneously, new mobility practices are encouraged among the public. Measures include the setting-up of information and awareness campaigns, marketing activities, the provision of buyer guides and vehicle labelling, education and training activities for vehicle-salespersons, mechanics and conversion-shopemployees. Lobbying activities, realisation of demonstration projects, development of target group specific EV offers and the marketing and demonstration of possibilities for changing mobility behaviour also play an important role.

A further supplementary instrument is to develop public transport in synergy with electric mobility by allowing interfaces with car-sharing services and vehicle rentals as well as by installing necessary (recharging) infrastructure and common tariff schemes of public transport in combination with individual, electric transport means.

Governments are likely to select a certain package of instruments with respect to the existing framework, the capability and financial capacity of the country. The capability depends on specific country characteristics, including the geographic and economic situation. To be effective, a policy package should combine all kinds of instruments in a comprehensive and balanced way: network management, framework conditions, economic incentives and fleet procurement, communication and diffusion, and multimodal transport policy. 


\section{Review of national policies}

This section explores governmental strategies and initiatives on a national level in order to reveal currently preferred deployed measures. Reasons for and trends of a policy framework for the support of EVs are shown. Mid- and long term objectives of discussed countries are sketched.

\subsection{Review by country}

\subsubsection{The European Union}

End of April 2010 the European Commission released the 'European strategy on clean and energy efficient vehicles' [4]. The strategy is purported to encourage the development and uptake of clean and energy efficient vehicles. Europe declares its aim to become market leader and technological champion for clean and energy efficient vehicles, while promoting sustainable growth and reducing the EU's dependency on fossil fuels and its emissions resulting from the transport sector.

The strategy envisages to continue and to revise the current regulatory framework laying down standards and regulations of vehicle emissions, to support $\mathrm{R} \& \mathrm{D}$ in green technologies, to support consumer information and market uptake by introducing EU-wide electro-mobility projects and to engage in international standardisation activities and dialogues. Concerning EVs specifically, the European Commission wants to make sure to achieve Europe-wide standards for communication and recharging infrastructure. Further, funding for EV infrastructure development on national and regional level shall be made available and ways for stimulating investment in infrastructure and EV services are to be defined. Life cycle analysis of different new vehicle technologies will be carried out in order to evaluate the impact of the increased requirement for lowcarbon electricity on the electricity supply system and on the grid. The EU will take initiatives for assuring sustainable secondary use of batteries and EVs' end of life. For this purpose research programs especially on recycling and reusing of batteries are promoted.

The European Roadmap 'Electrification of Road Transport' [5] released in October 2009 gives a consensus of major companies and organisations. In an introduction period till 2012, 200,000 (PH)EVs shall be deployed. Demonstration and field tests shall be carried out; first niche applications shall evolve. In an intermediate phase until 2016, 1 million EVs/PHEVs are to be deployed. Technology advancement and enlarged infrastructure shall allow the dissemination of the vehicles over various cities and regions. From 2018 onwards mass production of the new vehicles is to start, turning $(\mathrm{PH}) \mathrm{EVs}$, together with further battery advancements, sellable without any subsidy. 5 million vehicles shall be deployed by 2018 .
In November 2008 the European Commission launched the PPP Green Car Initiative [6]. By now EUR 5 billion (EUR 4 billion are provided as loans through the European Investment Bank) have been made available for the support of R\&D on technologies and infrastructures that are essential for achieving 'breakthroughs' in the use of renewable and non-polluting energy sources, safety and traffic fluidity. Projects related to fully electric and hybrid electric vehicles have gained of importance throughout the last years. Also the CIVITAS [7] program for cleaner and better transport in cities specifically defines 'clean fuels and vehicles' as one out of eight categories of measures. 25 projects throughout various European cities have been launched in this context. The most recent project focusing specifically on $(\mathrm{PH}) \mathrm{EV}$ s and operating on a large scale is the 4-year Green emotion project that was launched in March 2011. It unifies 42 partners from industry and the energy sector as well as electric vehicle manufacturers, municipalities, universities and research institutions. The aim is to exchange and expand know-how around the introduction of $(\mathrm{PH}) \mathrm{EVs}$ in selected regions within Europe. Smart grid developments, ICT solutions, different types of EVs and urban mobility concepts are taken into account. The total budget of the project is EUR 42 million, of which EUR 24 million are funded by the European Commission [8].

\subsubsection{Germany}

In January 2009 the German government approved the 'Economic Stimulus Package II', where one out of 14 resolutions specifically addresses electric mobility. Within this framework EUR 500 million has been made available for investments in R\&D in the general benefit of electric mobility for the years 2009-2011. Further, until the end of the current legislative period (in 2013), another EUR 1 billion has been made available [9].

In August 2009 a 'National Development Plan for Electric Mobility' (NEPE) [10] was adopted, which lays down the clear goal of deploying 1 million EVs by 2020. By 2030 more than 5 million EVs shall be deployed, by 2050 most urban transport shall do without fossil fuels. Until 2020 the development plan foresees the following three stages:

- A market preparation phase until 2011 mainly serves for advancements in research. Points of focus are energy storage systems, vehicle technology and system and grid integration. First recharge stations shall be deployed and several demonstration projects will be launched.

- A succeeding market escalation phase, lasting until 2016, then foresees the introduction of EVs into the market and a broader infrastructure installation that covers numerous towns. 
- From 2017 onwards a mass market of EVs shall be created. Mass production of EVs and (probably) lithium-ion batteries within Germany are envisaged.

The main stated goals of Germany are meeting energy and climate policy targets, developing a lead market for electric mobility, maintaining and expanding the country's competitiveness, and fostering new mobility practices in order to achieve a considerable improvement in the quality of life.

In May 2010 a national platform for electro-mobility (Nationale Plattform Elektromobiliät - NPE) was established in order to deliver concrete propositions that help achieve the goals set in the NEPE [10]. NPE published a second interim report in May 2011 [11], on the basis of which the federal government released a national government program [9]. It defines concrete measures for the support of R\&D activities, of the EV-system development, of education programs, standardization procedures and infrastructure and electricity generation development.

Besides an exemption of the circulation tax for a period of 5 years from the date of the first vehicle registration, no other fiscal measures specifically encouraging EV demand have been stipulated so far [12]. However, it is planned that all EVs registered before the end of 2015 are eligible for tax exemptions for a period of 10 years. Also the taxation regime of fleet vehicles (or vehicles with professional usage) will be adapted to the advantage of EVs [9].

\subsubsection{United Kingdom}

The United Kingdom wants to leave the technological development open to the market. Favouring of specific technologies is avoided. The Office for Low Emission Vehicles (OLEV) released a policy paper on 'Ultra-Low Carbon Vehicles in the UK' [13] in 2009, which, however, mainly refers to $(\mathrm{PH}) \mathrm{EVs}$. The policy paper defines the following strategy:

- Short term (-2015): Support is given to demonstration projects and to the transformation of urban centres to EV cities. Consumer incentives are implemented to stimulate demand.

- Medium term (2015-2020): Continued improvements to the efficiency of new cars are envisaged. Coverage of charging infrastructure is to be increased. (PH)EVs are produced on a large scale.

- Long term (2020+): From 2020 onwards, a continued roll-out of charging infrastructure shall take place. This shall allow the development of a mass market of ultra-low carbon vehicles that results in a complete decarbonisation of the road transport by 2050 .
The main incentives for the UK for investing into the development of (PH)EVs are of environmental and economic nature. The transportation sector shall be decarbonised, national economic competitiveness and growth shall be supported, and life, health and safety are to be improved.

As of mid-2010 the UK has already committed over $£ 450$ million of support to encourage the development and uptake of (PH)EVs. Over $£ 300$ million are provided over the life of the current parliament for the 'Plug-in car grant' [14] program, which supports motorists of an ultra-low carbon vehicle with a subsidy of up to $£ 5.000$ until 2014. Both, private consumers and businesses can benefit from the Plug-In Car Grant when purchasing a qualifying ultra-low emission car. Currently there are 10 vehicle models eligible for the grant, of which, however, not all are yet available on the market. In order to be eligible for the grant scheme, vehicles must conform to criteria released by the OLEV (which refer to the vehicle type, the carbon dioxide exhaust, the vehicle range, the minimum top speed, the warranty, the battery performance, the electric and crash safety). As of 30 September 2011, 786 claims have been made through the grant scheme.

A 'Low Carbon Vehicle Procurement Program' [15] is supported by altogether $£ 50$ million and aims to use the public sector's purchasing power to accelerate market introduction of lower carbon vehicle technologies.

With regards to recharge infrastructure, the current government published a strategy [16] that sets out (a) how to ease vehicle charging for individuals at home and at night and how to locate and use public charging points (b) how to ease the installation of recharge infrastructure by removing regulatory barriers and (c) how to include adequate policy in the National Planning Policy Framework in order to encourage local authorities to release local policies that help the development of recharge infrastructure at new domestic, workplace and retail developments. Within this framework the 'Plugged-in places' program [17] aims to create a critical mass of infrastructure for 8 pilot projects. 8.500 charge points are to be installed. Data derived from the program shall serve as evidence base about how to shape a national recharging infrastructure system. The 8 supported regions are the East of England, Greater Manchester, London, Midlands, Milton Keynes, North East, Northern Ireland and Scotland. $£ 30$ million were made available [16].

The 'Infrastructure grant program' [18] provides grants to encourage organisations to install refuelling or recharging stations for alternative fuels. R\&D support in the field of $(\mathrm{PH})$ EVs of more than $£ 220$ million is provided through the Technology Strategy Board for the 'Integrated Delivery Program' [19] and the 'Ultra Low carbon Vehicle Demonstrator Programme' [20]. In the framework of the demonstrator programme 340 new innovative cars were put on the road in various locations of the UK. It is believed to be Europe's largest real world trial of low carbon vehicles. The programme 
made $£ 25$ million available for the business-led demonstration projects, which are run by consortia including vehicle manufacturers, local authorities, power companies and universities. Attitudes and behaviours of consumers are analysed by logging of data. In September 2011 the initial findings after a 3-month trial period were published (see [21, 22].

Further, the UK government announced to increase fuel taxes till 2013. EVs do not pay any fuel duty or vehicle excise tax and are subject to the lowest percentage of the company car tax [23].

\subsubsection{Spain}

In April 2010 Spain set out an integrated strategy promoting the development of electric mobility. A related action plan released in November 2010 points out the priority for electric mobility in the near future. The goal is to have $70.000 \mathrm{EVs}$ in circulation by 2012 . $250.000 \mathrm{EVs}$ are to be deployed by $2014.85 \%$ of these vehicles are seen in large public and company fleets, the remaining $15 \%$ are expected in private vehicle ownership. Together with gasoline-electric (plug-in) hybrid cars, altogether 1 million low-emission cars shall be on Spanish roads by 2014. The main reasons for aiming at these numbers are to reduce carbon emissions and Spain's dependency on energy importations. Further, introducing EVs is seen as an important stimulus in innovation and as a necessary contribution to the sustainability of the transport system [24, 25].

In September 2009 the Spanish government announced to spend EUR 10 million on kick-starting the use of EVs until 2011 [25]. The hereby financed Movele project [26] aims to introduce 2,000 EVs of various categories across a broad range of companies, institutions and private individuals, for use in urban environments, and to set up 546 public recharging points (Seville - 75, Madrid - 280, Barcelona 191). Besides the cities of Seville, Madrid and Barcelona, also several regions and local authorities have individual plans for establishing recharging infrastructure. Until 2014 altogether 62.000 recharging points for private homes, 263.000 points in car parks, 12.150 points in public car parks and 6.200 points on public roads are to be established [27].

In April 2010 further EUR 590 million were announced for subsidies and tax breaks concerning the purchase of EVs. The subsidy covers $20 \%$ of the purchase price of an EV (up to a maximum amount of EUR 6.000) [24].

\subsubsection{Denmark}

The Danish government acknowledges that EVs can significantly contribute to a reduction in the use of fossil fuels. Next to environmental stakes, energy security is the main reason for this government to support the market penetration of EVs. The goal is to replace a quarter of the 2 million cars in circulation with electric cars by 2020 and achieve a penetration rate of $94 \%$ on the market of new vehicles at that epoch [28].

Due to a green tax policy [29] there is an extremely high registration taxation (of up to $180 \%$ ) on combustion engine cars. EVs are exempted from this taxation until 2015.

In February 2008 the Danish government signed an energy agreement, which features a test scheme for EVs [28]. The test scheme's goal is to generate new specific and practical experience with EVs and the required infrastructure. The test scheme shall also help shed light on the opportunities for integrating EVs as a flexible storage facility into the Danish electricity system. DKK 35 million ( $\sim$ EUR 4.5 million) have been set aside for the test scheme in the period 2008-2012.

In 2009 Denmark became after Israel the second country that fully cooperates with Better Place [30]. An extensive recharging and battery swap infrastructure is rolled out. 500,000 charging points and 150 battery swap stations are envisaged.

Further, also a large scale demonstration project [31] is taking place on the island of Bornholm. Especially the vehicle-to-grid concept is tested.

\subsubsection{France}

France has ambitious targets concerning EVs. Until 2015 the market share of EVs of newly sold vehicles shall have reached $7 \%$ (16\% in $2020,27 \%$ in 2025) and 450.000 vehicles shall have been deployed ( 2 million by $2020,4.5$ million by 2025) [32].

In October 2009 a national plan for the development of EVs was released. The document was updated in April 2010 and gives an overview of all (foreseen) initiatives in order to successfully launch a broad-scale introduction of EVs. The development of EVs is seen as a twofold opportunity in order to fight against climate change, while simultaneously restructuring an economic sector/the whole economy [33].

The 'Automobile Pact' released in February 2009, foresees a EUR 250 million loan for the industrialisation of decarbonised vehicles. The 'Grand Emprunt' (announced in December 2009) foresees EUR 750 million for the development of decarbonised vehicles. This funding will be invested in several research and deployment projects under the patronage of the French Environment and Energy Agency (ADEME). Specific funding has also been made available for the construction and development of a battery production factory with a capacity of up to 350,000 batteries. The eco-conception of batteries and their recycling are research priorities.

In order to guarantee EV demand to the biggest French auto manufacturers (Renault and PSA), a purchase group of 20 industry partners was formed that guarantees a demand of 50,000 vehicles within 5 years. In October 2011 first 
orders of the purchase group have been placed: Renault has received an order of 15.637 utility vehicles (Kangoo ZE electric) over the duration of 4 years - mainly to equip the vehicle fleet of La Poste. PSA received an order of 3.074 vehicles of its Peugeot Ion model [34].

In order to assure the supply of appropriate recharging infrastructure, laws have been released that oblige every new building equipped with parking units to connect these to electricity supply by 2012. Car parks at work places have to be equipped with electricity connections by 2015 . Further, EUR 60 million has been made available for the installation of 1,250 public recharging points around 20 agglomerations till 2012. By 2025 a recharging infrastructure of 9.9 million points shall have been established around France (thereof 9 million private points, 750,000 public normal charging and 150,000 public rapid charging points) [33].

EVs profit from the highest bonus of an emission based bonus/malus system, being EUR 5,000 per vehicle. This measure has been guaranteed at least until 2012.

A French-German working group succeeded in developing a joint approach to standardisation, which ensures the interoperability of EVs and charging infrastructures. The outlined recommendations will be put into action within the framework of a Franco-German pilot project in the region between Strasbourg, Karlsruhe, Mannheim and Stuttgart [35].

\subsubsection{Norway}

An action plan for the electrification of road transport (2009) that was commissioned by the Ministry of Transport and Communication sets the goal of attaining 200.000 EVs on Norwegian roads by 2020 (signifying approximately $10 \%$ of the current car fleet). The need of an accompanying public recharge infrastructure that allows normal, fast and quick charging has been identified and is estimated to lie at around 30.000 public charging points. Norway's current EV fleet shows with 4.200 vehicles the second highest EV penetration rate (after Monaco) when compared to the number of inhabitants. Most of these vehicles are privately owned. Norway stipulated comparatively strong fiscal and non-fiscal purchase incentives, both being defined on a national level (!): EVs have access to bus lanes, profit from free parking on public grounds and are exempted from the (comparatively high) VAT as well as from road and ferry tolling [36].

\subsubsection{USA}

The American Recovery and Reinvestment Act of 2009 (ARRA) [37] is the most recent legislative act that specifically supports the development and use of a variety of alternative fuel and advanced vehicle technologies. It shall fund research on and industrialization of alternative vehicles in order to put 1 million environmentally friendly vehicles on US roads by 2015 .

The main motives for the US government to support the development of alternative fuelled vehicles mainly lie in the energy security of the country. Further, it is stated that the US wants to compete with foreign nations in the race to be world leader on renewable energy, to create jobs and to hereby lay the foundation for lasting prosperity, to advance the economic recovery, and improve the environmental sustainability [38].

In 2009 President Obama announced that \$2.4 billion out of the ARRA budget are specifically dedicated to the acceleration of the manufacturing and deployment of batteries and EVs [38, 39]. 48 new advanced battery and electric drive component manufacturing and electric drive vehicle deployment projects in over 20 states are funded.

The ARRA dedicates funds to further programs/incentives that (partly) contribute to the development of EVs. Some important instances concerning EVs are [37]:

- The Qualified Plug-In Electric Drive Motor Vehicle Tax Credit that contributes between $\$ 2,500$ and $\$ 7,500$ to the purchase of a new qualified (PH)EV, depending on the battery capacity and the gross vehicle weight.

- The Alternative Fuel Infrastructure Tax Credit that subsidises the expenditures for installing alternative fuelling equipment. The credit amount goes up to $50 \%$ of the equipment costs (not to exceed $\$ 50,000$ ). Private consumers receive a tax credit of $\$ 2.000$.

- The Manufacturing Recovery Provisions Tax Credit - a $30 \%$ tax credit for investment in advanced energy property manufacturing facilities.

- The Support for fuel-efficient vehicles in the federal fleet - a $\$ 3$ billion fund for the acquisition of more fuelefficient vehicles for the federal fleet by September 30, 2011.

Most measures concerning alternative vehicles are, however, defined on different (mostly state) authority levels. Statistics show that California is the state that provides the widest set of incentives and implements the most stringent legislation concerning alternative fuels [40].

In the framework of the Advance Technology Vehicles Manufacturing Loan Program (ATVLP) [41], \$1.6 billion were accorded to Nissan North America to build advanced EVs and to build an advanced battery manufacturing facility. \$465 million were accorded to Tesla Motors to manufacture electric drive trains and EVs in California.

The US also engages in the U.S-China Electric Vehicles Initiative [42] that aims at developing joint standards and demonstration projects, a joint technical roadmap and jointly organised yearly forums to bring key stakeholders together. The Japan-U.S. Clean Energy Technologies Action Plan [43] 
encourages the development of mutually beneficial energy science and technology projects.

\subsubsection{Japan}

In April 2010 Japan released the 'Next Generation Vehicle Strategy 2010', [44]. New vehicle technologies are to be supported simultaneously until 2030. However, until the year 2050 a full-scale diffusion of (PH)EVs shall have taken place [45]. The cruising distance of EVs shall reach up to $500 \mathrm{~km}$ and battery costs shall have reduced to $1 / 40$ of the current price. By 2030 the governmental diffusion target is to achieve a next-generation vehicle percentage of $50-70 \%$ of newly sold vehicles. It is estimated that up to $30 \%$ could be made up by (PH)EVs. The remainder should be covered by hybrid, fuel cell or clean diesel vehicles [44].

The main objectives for creating a next-generation vehicle strategy were to improve fuel efficiency (and hereby to improve energy security), to reduce $\mathrm{CO} 2$ emissions, to diversify the energy mix, and to introduce next-generation vehicles to the market on a full-scale basis. The Japanese automobile industry shall hereby maintain its leadership in high-rate technical capacity on the global market by creating new industry sectors and by acquiring new markets. The country's economy and employment shall be driven and also the competitiveness of Japan's automotive industry is to be maintained [46].

The 'EV \& pHV Towns' concept [47, 48] is an implementation framework to demonstrate fully-fledged dissemination of EVs and PHEVs. In cooperation with municipalities, automobile manufacturers, power companies and local enterprises, an intensive development of infrastructure for $(\mathrm{PH}) \mathrm{EVs}$ is pursued in 8 different urban regions. Demand is initiated by the government, the municipalities and corporations; it is then extended to taxis or car-sharing systems; and finally to private users by fiscal incentives in automobile prices.

The Japanese government has introduced temporary tax reductions/exemptions for fuel-efficient vehicles lasting till April 2012. (PH)EVs are completely exempted from taxes [47].

\subsubsection{China}

In China a national strategy of leapfrogging to EVs emerged around 2008. The objective of having a manufacturing capacity of 500,000 new energy vehicles (pure electric, hybrid and other alternative energy vehicles) by 2011 was defined. The new cars shall represent $5 \%$ of annual new passenger car sales. The main drivers for Chinese government to push the development of new energy vehicles are to sustain the growth of the automobile industry, lessen the dependency on imported fossil fuels and to reduce the pollution caused by automobiles [49].

In the 11th 5 year plan (2007-2012), the Chinese Government set out a detailed roadmap for the development of EV technology. The 12th 5 year plan foresees an allocation of around EUR 18 million for battery development - a rather moderate sum though, especially when compared to other countries (e.g. the US budgeted \$ 1.5 billion as part of the American Reinvestment and Recovery Act). The key funding mechanism for research is the "863 Programme". In recent years, this fund has mostly supported the development of electric vehicles [50].

To stimulate usage of clean vehicles in the public transport sector, the government announced a package of measures in 13 pilot cities that belong to the first batch of ' 10 cities, 1,000 vehicles' project. Over a three year period (start in January 2009) pilot cities have been selected each year that put 1,000 hybrid or pure EVs on the road [49]. In early 200913 cities were selected, in June 20107 more cities were added and finally, in July 2011 the program was expanded to 25 cities. In these 25 cities, public service vehicles receive significant national government subsidies. Since June 2010, 5 cities (Shanghai, Changchun, Shenzhen, Hangzhou, and Hefei) also offer subsidies for approved private electric and other new energy vehicles in the range of approximately EUR 5.500 (maximum for PHEVs) and EUR 6.600 (maximum for BEVs) [50].

New energy vehicles are gradually integrated into the national government vehicle purchase system [49].

\subsubsection{India}

In December 2006 the Ministry released the 'Automotive Mission Plan 2006-2016' [51], which lays down the roadmap for future development in the automotive industry. The manufacturing and assembling of fuel efficient and hybrid vehicles appropriate for the Indian market is a recommended measure. Conversion of vehicles to alternative fuels is to be encouraged and innovative $R \& D$ projects are to be supported.

India has the ambitious electric car manufacturer REVA Electric Car Company (RECC), which designs, develops, manufactures and sells EVs. Its chairman strongly calls for appropriate government support that could help transform the landscape of urban India by reducing pollution, improving public health, creating employment opportunities and impacting society. According to RECC, EVs have not gained popularity owing to lack of adequate and timely support from central and state governments. However, RECC aims to have $100,000 \mathrm{EVs}$ on the roads by 2020 [52].

In late 2010 the Ministry of New and Renewable Energy has decided to offer EV incentives in order to boost their sales. The ministry pays up to $20 \%$ of the ex-factory price 
of EVs, which the manufacturers are expected to pass on to buyers. In return, the manufacturers have to assure that at least $30 \%$ of their supply parts stem from Indian enterprises. This incentive scheme may be extended as part of the 12th five-year plan, which begins in 2012-13. Further, budget has been made available to launch a "National Mission for Hybrid and Electric Vehicles" that brings all EV stakeholders together [53].

\subsection{Synthesis}

Each country under review has assigned a set of stakes to the development of EVs, including primarily the reduction of environmental impacts - on climate and local quality of life. This stake is common to all countries. Two other stakes are invoked depending on the country: energy security and industrial policy. Only the stake of industrial policy makes an issue of international competition. The climate stake is global, whereas the production of green energy is mostly a national matter.

Concerning vehicle deployment objectives, countries show somewhat more and less ambitious goals. Figure 1 gives an overview of deployment objectives defined for the year 2020 (or 2015 for some exceptions) in total numbers (left) and in percent of the current car fleet (right), which renders comparisons between countries more valid.

It can be seen that the most ambitious target of reviewed countries is clearly the one of Denmark. Denmark is overall an extreme case due to the high vehicle purchase tax applied to conventional vehicles but not to EVs. Furthermore, Denmark sees large potential for EVs with regards to a more efficient exploitation of its renewable energy sources (mainly wind energy). However, also France and Austria show comparatively ambitious targets in the European context. The goal of China is so far difficult to assess and not to be brought in context with European deployment goals. Since the total vehicle fleet is previewed to increase immensely throughout the next decade, the percentage in terms of the current vehicle fleet gives certainly a distorted picture of what will actually happen.
Most governments address simultaneously the development of demand and that of a charging infrastructure, plus R\&D objectives if there is a stake of industrial policy. Comprehensive policy packages are devised, which include framework design and equipment standardization, demand stimulation using fiscal incentives, cooperative procurement of large fleets of vehicles, the implementation of charging spots and the deployment of pilot projects in selected areas. The packages are aimed to promote alternative energy vehicles, basically pure electric or plug-in hybrid, sometimes also hydrogen or bio-fuel.

Table 1 gives a qualitative overview of (mainly) fiscal measures that either target the enhancement of EV demand or the development of accompanying recharging infrastructure. A slight disequilibrium in favour of vehicle demand can be noticed. However, the last year has shown that more and more often costly while less straightforward initiatives concerning infrastructure development have been defined. It has been acknowledged that the availability of (public) recharge infrastructure will be a stringent criterion for many vehicle purchasers - also if public infrastructure will only serve as reassuring secondary recharging option for most vehicle users.

Most countries consider explicitly a development path made up of three steps: from Initialization by pilot projects and procurement initiatives, to a Long Run step where EVs hold a large share of the car stock, passing by a Medium Run step which involves taxi and shared-car fleets. The development of green energy sources is mentioned in orientation documents but does not seem to be planned jointly with the first stage of the implementation path.

Concerning the defined deployment objectives and often intermediate deployment goals, it goes without saying that great uncertainty exists whether these objectives are feasible (or, alternatively, easily outnumbered). EV uptake rates are extremely difficult to forecast due to the many uncertainties that come with the introduction of a new technology. Customer acceptance is difficult to assess, even more so since the future offer (e.g. concerning the durability of the equipment, its technological features, its residual value) and its actual costs are not yet entirely
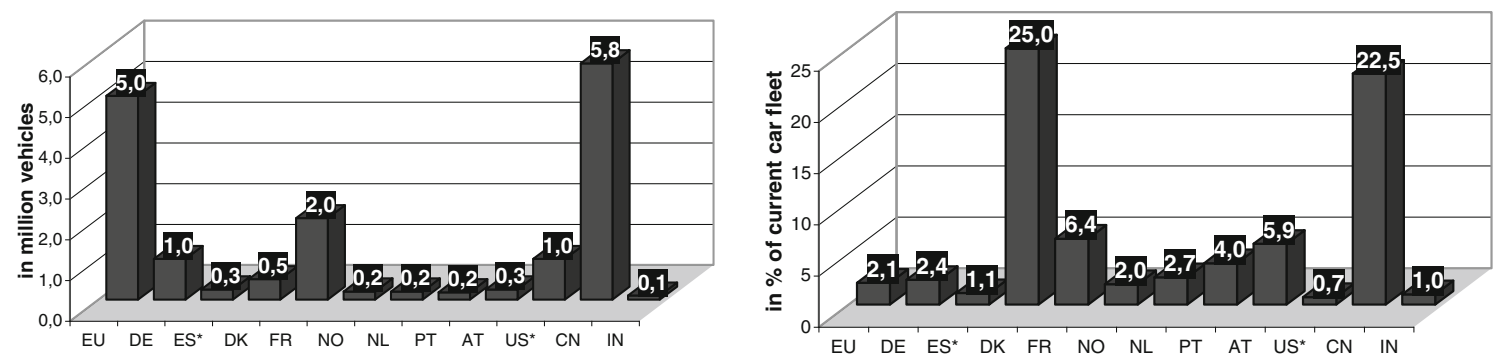

Fig. 1 (PH)EV deployment goals by country for 2020 (* for 2015); left: in total numbers, right: in percentage of the current vehicle fleet 
Table 1 Qualitative overview of deployed policy measures targeting vehicle demand and infrastructure deployment per country

\begin{tabular}{|c|c|c|c|c|c|c|c|c|c|}
\hline & \multicolumn{6}{|c|}{ Enhancing vehicle demand } & \multicolumn{3}{|c|}{ Infra. Deployment } \\
\hline & $\begin{array}{l}\text { Purchase } \\
\text { subsidies }\end{array}$ & $\begin{array}{l}\text { Taxation } \\
\text { incentives }\end{array}$ & $\begin{array}{l}\text { Less } \\
\text { insurance costs }\end{array}$ & $\begin{array}{l}\text { Reduced/No } \\
\text { parking fees }\end{array}$ & $\begin{array}{l}\text { Use of public } \\
\text { transport lanes }\end{array}$ & $\begin{array}{l}\text { Free } \\
\text { PT pass }\end{array}$ & $\begin{array}{l}\text { Subsidies for } \\
\text { infra uptake }\end{array}$ & $\begin{array}{l}\text { Public funding for } \\
\text { infra development }\end{array}$ & $\begin{array}{l}\text { Tax deductions } \\
\text { for infra uptake }\end{array}$ \\
\hline $\mathrm{DE}$ & & ++ & & & & & & & \\
\hline UK & ++ & ++ & & $++*$ & & & ++ & ++ & \\
\hline ES & ++ & + & & & & & & & \\
\hline DK & & +++ & & ++ & & & & & \\
\hline FR & ++ & & & $++*$ & & & & ++ & ++ \\
\hline NO & & +++ & & ++ & ++ & & & & \\
\hline NL & $+*$ & ++ & & $+++*$ & & & $+*$ & + & ++ \\
\hline IT & ++ & ++ & + & $++*$ & & & & & \\
\hline PT & + & ++ & & & & & & ++ & \\
\hline AT & & ++ & + & & & $++*$ & & & \\
\hline US & ++ & & & & & & ++ & & \\
\hline JP & + & ++ & & & & & & & \\
\hline $\mathrm{CN}$ & $++^{*}$ & $++*$ & & & & & & $++*$ & \\
\hline
\end{tabular}

*Policies on local level

certain. Next to these uncertainties that a potential customer has to face when contemplating to buy an EV come the additional uncertainties related to future public policy measures and the general market development (especially with regard to oil and electricity prices). Both will have major impact on the economic viability of an EV compared to its conventional counterpart. Public policy goals that have partly already been defined a couple of years ago-a time when exact product (and service) offers of EVs have been even more uncertain-can therefore only be taken as desired penetration rates. However, these penetration rates serve as reference point for the definition of public policy measures. Whether these measures will be sufficient for achieving each country's objective is to be observed in the upcoming years. In this early stage reliable assessments can not be made. Recently developed demand models (as e.g. [54-57]) therefore often work with scenario analyses that help apprehend the possible magnitude of differing EV penetration rates due to changing input parameters. The fact that resulting ranges often turn out to be quite large confirms the difficulty of making reliable forecasts. This is even more so the case when applying aggregate models that hamper the inclusion of local parameters - parameters that are, however, significant when forecasting local mobility matters and local policy impacts. For the Paris region we therefore propose a disaggregate approach combined with empirical evidence [58].

However, from today's point of view also some certainties can be identified:

On the one hand, it can be foreseen that there will be a very likely high potential for EVs in company fleets. The combination of usually very high yearly mileage and the specific usage patterns (often predetermined, repetitive and short trips) of these vehicles will render the deployment of EVs advantageous: Economic viability will be met, while autonomy issues (due to the limited battery capacity) can be neglected and parking and recharge infrastructure needs can be met. The adapted vehicle offer (already provided by vehicle manufacturers) will specifically encourage the demand for EVs in professional fleets. France shows first large scale orders of the formed industrial purchase group. The actual compatibility of and satisfaction with EVs in professional fleets will be readily assessable in 2 years.

On the other hand, foreseeable potential lies in shared vehicle fleets. In adequate regions (e.g. sub-urban regions) that (a) show trip patterns of inhabitants that are conform with an EV's autonomy and that (b) are suitably provided with public recharge infrastructure, the typical hurdles of economic viability and battery capacity of an EV can be overcome. Furthermore, shared vehicle fleets will serve as great mean of publicity among private vehicle owners and help (in the same way as professional fleets) bring costs of EVs down due to increased demand. The economic viability of EVs in private vehicle ownership can therefore be facilitated.

The successful deployment of shared vehicle services will rely to a big part on local initiatives, often heavily supported by local authorities. Only this way, entrance barriers (such as the need for public space) can be surmounted. The following section therefore explores some examples of local initiatives that are seen as having potential for a successful regional EV deployment and that serve as interesting case studies. 


\section{Regional projects and policies}

\subsection{London's EV delivery plan}

The Mayor of London launched an Electric Vehicle Delivery Plan in May 2009 [59, 60]. It sets out the roadmap to deploy charging infrastructure for privately-owned EVs up to 2015. Altogether 25,000 charging points shall be installed and 100,000 EVs are targeted on London's roads. The main reasons for the city of London to promote EV development are to reduce carbon emissions, to improve air quality and to reduce noise.

\subsubsection{Infrastructure}

The city of London envisages making three main types of charging points in the public access charging network available. Slow charging points (6-8 h charging time), fast charging points (30 min-3 h charging time), and rapid charging points (15-20 min charging time, battery swap system) shall be deployed. The development of the private charging network, in residential homes, at workplaces and for new developments will be supported.

Besides residential off-street charging points, installations at private car parks and customer car parks take the biggest share in the network (altogether 22,500 installations). The public charging network is envisaged to comprise 500 onstreet charging points and 2.000 installations in publicly accessible car parks. The main goal is to ensure that every Londoner will be no more than one mile from the nearest EV charging point by 2015 .

\subsubsection{Vehicles}

London aims to increase the number of EVs on the capital's streets as soon as possible to 100.000 vehicles (or 5\% of London's fleet). To achieve this target the city will continue with EV trials and to increase the share of EVs in the Greater London Area (GLA) group fleet. It will also encourage the use of EVs amongst its suppliers. EV options for the wider public transport, as e.g. for taxis, private hire vehicles and buses, shall be developed and the private sector shall be encouraged by incentives to acquire EVs and a marketing initiative.

\subsubsection{Incentives, marketing and communication}

The city of London supplies the EV users with incentives that complement the national UK ones. A number of boroughs offer subsidised parking for EVs, saving the user up to $£ 6,000$ a year. Also, there is a $100 \%$ congestion charging discount for EVs (being worth up to $£ 1,700$ per year for regular travellers).
For marketing and communication purposes, a strong and easily recognisable brand for EVs in London will be developed. A pan-London interactive web site will be developed that provides exhaustive information on EVs in London and e.g. on the location of vacant charge points. A call centre for help and advice and to report any issues is envisioned.

It is foreseen that the EV scheme will initially operate as a flat fee membership scheme, whereby EV owners pay an annual membership fee to access any of the 2,500 publicly accessible charging points. The aspiration is, however, that the scheme moves to a 'pay as you go' model once there is a sufficient number of EVs in London.

\subsection{Germany’s model regions [61, 62]}

Out of Germany's funding of EUR 500 million for the development of EVs, EUR 115 million are allocated to the establishment of 8 electro-mobility model regions. Stakeholders of science, industry and all participating authorities (regions, cities, communities) work closely together to ensure that electric mobility becomes an integral part of the transport system.

Model regions refer much to centres of excellence, where EV related research is carried out, where incitation to new research companies in these fields are given, where vehicles and infrastructure are developed and manufactured and where test fleets are employed and evaluated.

\subsubsection{North Rhine-Westphalia including model region Rhine-Ruhr}

One of the model regions is the Rhine-Ruhr area, located in the region of North Rhine-Westphalia (NRW). NRW set the goal of bringing at least 250.000 electrically powered vehicles to the market. They want to significantly increase the market share of suppliers from NRW in the overall German market for electric mobility and promote the settlement of new automobile manufacturers in order to utilize the market opportunities. EVs shall be developed to market readiness and market launch.

For this purpose NRW wants to attract players in industry and science to settle in their region and therefore promotes EV directed activities by EUR 60 million (additional to the existent federal funding of the German government).

NRW attracts with an already experienced 'auto cluster'. 12 universities offer automotive-related studies and conduct research on behalf of the automotive sector. Electricity supply is covered by three of the five largest German supply companies based in NRW. The establishment of 
customer-friendly charging stations has begun. There are about 25 institutional facilities and private enterprises that work in the field of battery technology. Around 40 institutes and private enterprises work in the field of automotive engineering for EVs. 30 players are engaged in the field of developing infrastructures and networks.

The model region Rhine-Ruhr focuses on the introduction of individual fleets and public fleets (buses, taxis etc.). Also car sharing models and other new mobility concepts shall be developed, tested and supported by sufficiently broad scientific activities. Within the framework of 7 'starter' projects, $220 \mathrm{EVs}$ are deployed until mid 2010. Until mid 2011 the first test phase shall be completed and successive project plans shall be derived and planned.

\subsection{VLOTTE project, Vorarlberg, Austria [63]}

VLOTTE is the project title of an EV demonstration and testing program taking place in the Western part of Austria, Vorarlberg, since August 2009. It belongs to the biggest EV model regions in Europe.

In 2008 the Austrian Climate and Energy Fund selected Vorarlberg to become a model region of electric mobility and appointed EUR 4.7 million to its development. The "backbone" of the region is the Vorarlberg Rhine Valley. The Rhine Valley is characterized by a relatively low population density and a simultaneous homogeneity of the settlement structure: an urban-sprawled landscape.

In the year $2009100 \mathrm{EVs}$ were distributed and assigned to interested parties of an exclusive circle: 40 cars were given to companies, 40 to public institutions, non-profit organisations and associations and 20 to private users. The customer is offered a "mobility card" for approximately $500 €$ a month (depending on the vehicle). The mobility card includes, apart from the leasing of the car, maintenance costs of the electric parts, a railway pass of the Vorarlberg Public Transport System and the free-of-charge refilling at all public energy recharging stations. After 4 years the car is purchased by the customer for a residual value of $25 \%$ of the initial purchase price. In addition, VLOTTE-customers get free membership to the Austrian Automobile Association.

\subsubsection{Vehicles and energy supply}

Different types of vehicles have been supplied to the project participants. Most of them were produced by the Norwegian car producer TH!NK. All of the VLOTTE vehicles use Sodium-nickel batteries.

The energy used for vehicle operation is compensated for by regional, renewable energy production - mainly from solar panels specifically installed for the project.

\subsubsection{Charging and its infrastructure}

The vehicles can be charged using any ordinary electricity plug. The regional electricity supplier offers reduced tariffs at night. Charging takes on average $7-8 \mathrm{~h}$, which is drastically reduced if 3 phase-current is available.

Furthermore every project participant has the possibility to charge his vehicle for free on the public charging infrastructure network in Vorarlberg (which currently comprises 32 charging stations), in Germany, Switzerland and Liechtenstein. Both the cars and the filling stations got equipped with measuring devices in order to analyse the energy demand on a disaggregate basis. The collected data are used to decide upon expanding the charging network.

\subsubsection{Results and outlook}

Within almost a year the VLOTTE vehicles made more than $150.000 \mathrm{~km}$. However, a better result could have been achieved if sufficient vehicles had been available. More than 200 interested people had to be short-listed due to insufficient supply of EVs.

The success of the project led to a second step, VLOTTE II. Here, the focus has been given to the establishment of so-called 'mobility-hubs' - vehicle sharing points where besides EVs also electric scooters and electric bikes can be hired. The VLOTTE fleet has been expanded to 250 vehicles; two-wheelers are complemented. The number of charging points has been augmented, the supplied electricity still stems from renewable energy sources deployed in the region.

\subsection{Provisional synthesis}

Three cases make a limited set of instances. Let us nevertheless identify first the common features then some peculiarities.

The common features pertain to (a) the stakes of environment preservation and the improvement of local quality of life; (b) the objectives to foster electric mobility and to provide a charging infrastructure.

Industrial policy including $R \& D$ is a distinctive feature of the Rhine-Ruhr region.

The Austrian, Vorarlberg case is remarkable in two features: first, the local production of green electricity to supply the power required by the fleet of EVs; second, the cooperative approach that involves a wide range of actors.

As of now, the three cases correspond to the implementation of pilot projects with several tens or hundreds of vehicles. They benefit from substantial public funding, so the economic performance of their EVs is not yet demonstrated. 


\section{A concluding look forward}

Following this review of national policies and regional plans, let us pick up the families of issues and discuss them from a sustainable development perspective, and from the perspective of limiting the environmental impact of car transport.

\subsection{Towards an economics of functionality in the sphere of mobility}

The electric vehicle offers potential users an economic advantage if the additional acquisition cost is offset by savings on vehicle use, which requires significant mileage to be covered. This may suit certain categories of private users, or services providing shared vehicles, which fall within the category of an "economics of functionality".

In addition, recharging systems constitute an additional infrastructure, which would increase the role of infrastructure in automobile transportation and spread its use more widely across users.

Finally, the size of the vehicle stock and charging infrastructure will need to be matched to the area, based on its mobility needs and its financial and renewable energy resources. The transition to electric vehicles could offer an opportunity to design an automobile system of appropriate dimensions.

\subsection{Technological and industrial factors}

The technological factors relate partly to the vehicle and its components, in particular the production of cheaper and more efficient batteries, and partly to the vehicle's external components, in the charging infrastructures (fast charging or battery swap systems) and the interface between user and system. This interface would need to cover several aspects:

- The interface for drivers, who plan their journeys and have to manage range constraints by scheduling charging stops that may influence their routes and even their destinations.

- The interface for the user of a shared vehicle service, such as remote vehicle or parking reservation systems and tariff management systems.

- The interface for battery holders, to offer economical charging and possibly optimise the cost of global domestic electricity consumption.

- The interface for managers of electric vehicle fleets, to ensure that an adequate number of sufficiently charged vehicles are available at all times and at the right place.

- The interface for operators of shared vehicle services, to optimise vehicle distribution and encourage users to contribute to vehicle repositioning in the depots, and also perhaps to manage real-time vehicle sharing for high-demand routes.

These interfaces have a dual software and hardware form, with on-board and/or centralised control units. The ergonomics of all the different user interfaces need to be as simple as possible, in order to avoid increasing the pressure on range and reservation constraints.

For the future of the transportation network, two types of interface seem crucial: the shared vehicle interface, which is critical for the co-evolution of operations and customers with their patterns of usage; and the interfaces with users to facilitate connections with other transportation modes (in particular parking and mass transit systems). Here, we are back with the question of how mobility is organised: there is likely to be a shift towards more considered and more rational use of the different modes of transportation.

We referred above to the industrial issues in terms of vehicle production and renewal. Other industrial factors include interface production and management and above all the running of vehicle recharge or rental services.

\subsection{Towards closer integration between transportation} and energy supply

Ultimately, electric mobility is motivated by climate and energy concerns. At the global level, significant expansion would require corresponding expansion in the production of low carbon electricity, generating a domino effect for other electricity requirements. A large stock of batteries will form a distributed, but globally huge, energy storage resource: they offer potentially significant synergies with energy production from green but inconsistent sources such as solar and wind power.

At the disaggregate level, fast vehicle charging will place large numbers of intense, localised demands on the national power grid. The power grid will need to evolve accordingly, and potentially even more to allow energy to be uploaded from the batteries, if they become media for distributed electricity storage. This development seems consistent with the integration of local green electricity production, and with "domestic" electricity management systems, under which individual households will control their own electricity production, storage and consumption.

Innovative and stimulating prospects for planning departments and citizens alike!

Open Access This article is distributed under the terms of the Creative Commons Attribution License which permits any use, 
distribution and reproduction in any medium, provided the original author(s) and source are credited.

\section{References}

1. International Energy Agency (2004) Deployment strategies for hybrid, electric and alternative fuel vehicles. Annex VIII/XXI

2. Sustainable Energy Ireland (2008) Review of worldwide experiences in the use and measures to stimulate the uptake of battery electric and hybrid electric vehicles, Report of the AEA Energy and Climate Change Consultancy, Version 2, Ireland

3. Austrian Ministry of Transport, Innovation and Technology (2010) Strategie und Instrumente sowie prioritaere Anwender- und Einsatzbereiche fuer den Nationalen Einfuehrungsplan Elektromobilitaet, Austria

4. European Commission (2010) European strategy on clean and energy efficient vehicles, Communication from the Commission to the European Parliament, The Council and the European Economic and Social Committee, Brussels

5. ERTRAC, EPoSS, SmartGrids (2009) European roadmap electrification of road transport

6. Green Car Initiative, http://www.green-cars-initiative.eu/ (29-10-2011)

7. CIVITAS Initiative, http://www.civitas-initiative.org/main.phtml? lan=en $(29-10-2011)$

8. Green emotion project, http://www.greenemotion-project.eu (24-10-2011)

9. German Federal Government (2011) Regierungsprogramm Elektromobilität, May 18. Online accessible via http://www.bmbf.de/ pubRD/programm_elektromobilitaet.pdf (30-10-2011)

10. German Federal Government (2009) Nationaler Entwicklungsplan Elektromobilität (NEPE), Germany

11. Nationale Plattform Elektromobilität (2011) Zweiter Bericht der Nationalen Plattform Elektromobilität, Berlin

12. ACEA (2011) Overview of purchase and tax incentives for electric vehicles in the EU. Online accessible via http://www. acea.be/images/uploads/files/20110330_EV_tax_overview.pdf (30-10-2011)

13. UK Department for Transport; Department for Business, Enterprise and Regulatory Reform; Department for Innovation, Universities and Skills (2009) Ultra-low carbon vehicles in the UK, UK

14. UK Plug-In Car Grant, http://www.dft.gov.uk/topics/sustainable/ olev/plug-in-car-grant/ (29-10-2011)

15. UK Low Carbon Vehicle Procurement Program, http://www. lcvpp.org.uk/ (29-10-2011)

16. UK Department for Transport (2011) Making the connection: the plug-in vehicle infrastructure strategy, online accessible via http:// www.dft.gov.uk/publications/plug-in-vehicle-infrastructure-strategy (29-10-2011)

17. UK Plugged-In Places, http://www.dft.gov.uk/pgr/sustainable/ olev/infrastructure/ (29-10-2011)

18. Infrastructure Grant Program, http://www.cenex.co.uk/programmes/ igp (31-10-2011)

19. Integrated Delivery Program, http://www.innovateuk.org/ourstrategy/ innovationplatforms/lowcarbonvehicles/integrateddeliveryprogramme. ashx (31-10-2011)

20. Ultra Low carbon Vehicle Demonstrator Programme, http://www. eco-rally.org/ultra_low_carbon_vehicle_demonstrator_projects (29-10-2011)

21. Technology Strategy Board (2011) Initial findings from the ultra low carbon vehicle demonstrator programme - how quickly did users adapt?, UK. Online available via http://www.innovateuk.org/ assets/pdf/press-releases/ulcv_reportaug11.pdf (29-10-2011).

22. Technology Strategy Board, Ultra Low Carbon Vehicle Demonstrator Programme, http://www.innovateuk.org/ourstrategy/ innovationplatforms/lowcarbonvehicles/ultralowcarbonvehiclede monstratorashx (29-10-2011).

23. Department for Transport (2009) Low carbon transport: a greener future - a carbon reduction strategy for transport, UK

24. DowJones (2010) Spain pledges EUR 590 million to boost use of electric cars, published on April 6, accessible online via http://www.easybourse.com/bourse/actualite/news/813665/ spain-pledges-eur590-million-to-boost-use-of-electric-cars.html (29-10-2011)

25. Guardian (2009) Madrid reverses the chargers with electric car plan, published on September 8, accessible online via http://www. guardian.co.uk/environment/2009/sep/08 /electric-car-plan-spain (15-04-2010)

26. Ministry of Industry, Tourism and Trade, Movele Cities, http:// enermanos.es/index.php /mod.pags/mem.detalle/relcategoria.1029/ id.419/relmenu.52/lang.uk (29-10-2011)

27. Clean Vehicle Europe, http://www.cleanvehicle.eu/info-per-countryand-eu-policy/member-states/spain/national-level/ (29-10-2011)

28. Ministry of Climate and Energy (2009) Electric cars in Denmark, Copenhagen, August 27, accessible online via http:// www.kemin.dk/electric_cars_in_denmark_transport_scheme_test. htm (14-05-2010)

29. Ministry of Foreign Affairs (2009) Test country for electric cars the tale of the ugly electric car, October 27 , online accessible via http://www.netpublikationer.dk/um/9517/html/ chapter02. htm (31-10-2011)

30. Better Place Israel, http://www.betterplace.com/global-progressisrael (31-10-2011)

31. Guardian 2009. Denmark to power electric cars by wind in vehicle-to-grid experiment, June 19, online accessible via http:// www.guardian.co.uk/environment /2009/jun/19/denmark-windelectric-cars (14-05-2010)

32. French Ministry of Ecology, Energy and sustainable development (2009) Groupe de Travail sur les Infrastructures de recharge pour les véhicules électriques ou hybrides rechargeables, Presentation

33. French Ministry of Ecology, Energy and sustainable development (2010) Grenelle Environnement - Les Avancées du plan de développement des véhicules électriques et hybrides, Paris, France

34. Le Figaro (2011) Renault gagne un marché de 15.600 voitures électriques, October 28, online accessible via http://www.lefigaro. $\mathrm{fr} /$ societes/2011/10/28/04015-20111028ARTFIG00463-1-etatachete-15600-kangoo-electriques-a-renault.php (29-10-2011)

35. French Ministry of Economy and Industry (2010) Résultat des discussions du groupe de travail franco-allemand sur les infrastructures de charge, January 26, online accessible via http:// www.industrie.gouv.fr/liste index/mobiliteelec 20100212.htm (2910-2011)

36. Solvi E, Norbech T (2011) The Norwegian model for financing, building and operating charging infrastructure for electric vehicles, Norwegian Public Roads Administration, Presented at the World Road Congress 2011, Mexico City

37. The American Recovery and Reinvestment Act (ARRA) (2009) Accessible via http://publicservice.evendon.com/RecoveryBill1M. htm (30-10-2011)

38. US Department of Energy, Office of Public Affairs (2009) President Obama announces \$2.4 Billion in funding to support next generation electric vehicles, Press release ((202) 586-4940), March 19, US

39. US Department of Energy, Office of Public Affairs (2009) President Obama announces $\$ 2.4$ Billion in grants to accelerate the manufacturing and deployment of the next generation of U.S. batteries and electric vehicles, Press release ((202) 586-4940), August 5, US

40. US Department of Energy, Alternative Fuels and Advanced Vehicles Data Centre, http://www.afdc.energy.gov/afdc/laws/ search (31-10-2011) 
41. US Department of Energy, Office of Public Affairs (2009) Obama administration awards first three auto loans for advanced technologies to ford motor company, Nissan motors and Tesla motors, Press reference ((202) 586-4940), June 23, US

42. The White House (2009) FACT SHEET: U.S.-China electric vehicles initiative, office of the Press Secretary, November 17, US

43. Japan Ministry of Economy, Trade and Industry, US Department of Energy (2009) Japan - U.S. clean energy technology action plan, Press Release, November, US/Japan

44. Japan Ministry of Economy, Trade and Industry (2010) Announcement of the next-generation vehicle strategy 2010, April 12, online accessible via http://www.meti.go.jp/english/press/data/20100412_02. html (31-10-2011)

45. Ministry of Economy, Trade and Industry (2009) Hydrogen and vehicle technology policy in Japan, hydrogen and fuel cell promotion office, agency for natural resources and energy, Presentation, May 18, 2009

46. Ministry of Economy, Trade and Industry, 2010. Announcement of the Next-Generation Vehicle Strategy 2010, Automobile Division, Manufacturing Industries Bureau, Press Release, April 12, Japan.

47. Hosaka S (2010) Views and policies on Japan's automotive industry', ministry of economy, trade and industry, automobile division manufacturing board, presentation held at the EU-Japan centre for industrial cooperation at the seminar on making green cars a reality: policies and initiatives in the EU and Japan, 25 February, Tokyo, Japan

48. Ministry of Economy, Trade and Industry (2010) Announcement of 'EV \& pHV Towns', automobile division, manufacturing industries bureau, Press Release, March 31, Japan

49. Wang H, Kimble C (2010) Leapfrogging to electric vehicles: challenges of governance in China's automobile industry, prepared for the 18th GERPISA International Colloquium on 'the greening of the global auto industry in a period of crisis', hosted by the Wissenschaftszentrum Berlin fuer Sozialforschung Gemeinnuetzige Gesellschaft, 9-11 June, Berlin, Germany

50. United Nations Department of Economic and Social Affairs (2011) Electric vehicles in the context of sustainable development in China, Background Paper No.9 CSD19/2011/BP9, May, New York

51. Ministry of Heavy Industries and Public Enterprises (2006) Automotive mission plan 2006-2016, New Delhi, India

52. Maini CK (2007) The future of electric vehicles in India, published on behalf of federation of automobile dealers associations of India, online accessible via http://www.fadaweb.com/ electric_vehicles.htm. (17-06-2010)

53. Panchabuta - Cleantech \& Renewable Energy in India, India launches unique green car policy, online accessible via http:// panchabuta.com/tag/national-electric-vehicle-policy/ (31-10-2011)

54. Delft CE (2011) Impacts of electric vehicles - deliverable 4: economic analysis and business models, April, online accessible via www.cedelft.eu (20-09-2011)

55. The Boston Consulting Group (2009) The comeback of the electric car? - How real, how soon, and what must happen next

56. Commissariat Général au Développement Durable (2011) Les véhicules électriques en perspective: analyse coûts-avantages et demande potentielle, Etude N 41

57. European School of Management and Technology (ESMT) (2011) Marktmodell Elektromobilität, online accessible via http://www. mmem.eu/ (31-10-2011)

58. Windisch E (2011) The potential for privately owned electric cars in the Paris region: a disaggregate approach, presented at the European Electric Vehicle Congress (EEVC) 26-28 Octobre, Brussels, BE

59. Greater London Authority (2009) London's electric vehicle infrastructure strategy, draft for consultation, UK

60. Greater London Authority (2009) An electric vehicle delivery plan for London, Presentation, UK

61. EnergieAgentur.NRW (2009) Modellregion Rhein-Ruhr, Duesseldorf, D

62. NRW.INVEST GmbH (2009) Model region for electric mobility North Rhine-Westphalia, Economic Development Agency of the German State of North Rhine-Westphalia (NRW), Duesseldorf, D 63. Project 'VLOTTE', www.vlotte.at (31-10-2011) 